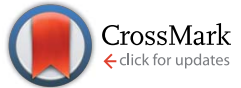

Cite this: Chem. Sci., 2016, 7, 6176

Received 25th April 2016

Accepted 7th June 2016

DOI: $10.1039 /$ c6sc01795a

www.rsc.org/chemicalscience

\title{
Benzo[4,5]cyclohepta[1,2-b]fluorene: an isomeric motif for pentacene containing linearly fused five-, six- and seven-membered rings $\dagger$
}

\author{
Xuejin Yang, $\dot{t}^{\mathrm{a}}$ Xueliang Shi, $\dot{t}^{\mathrm{b}}$ Naoki Aratani, ${ }^{\mathrm{c}}$ Théo P. Gonçalves, ${ }^{\mathrm{d}}$ Kuo-Wei Huang, ${ }^{\mathrm{d}}$
} Hiroko Yamada, ${ }^{c}$ Chunyan Chi ${ }^{\star b}$ and Qian Miao*a

\begin{abstract}
Benzo[4,5]cyclohepta[1,2-b]fluorene (5a), a new $\pi$-conjugated polycyclic hydrocarbon containing linearly fused six-, five-, six-, seven- and six-membered rings $\left(C_{6}-C_{5}-C_{6}-C_{7}-C_{6}\right)$, was designed and its stable derivatives $5 \mathrm{~b}$ and $5 \mathrm{c}$ were synthesized. With $22 \pi$ electrons, $5 \mathrm{a}$ is an isomer of pentacene with quinoidal, dipolar ionic and diradical resonance forms. Molecules $5 \mathrm{~b}$ and $5 \mathrm{c}$ were experimentally investigated with cyclic voltammetry, electronic absorption spectroscopy and X-ray crystallographic analysis, and theoretically studied by calculating the NICS value, diradical character and dipole moment. A comparison of $5 \mathrm{a}-\mathrm{c}$ with pentacene and other pentacene analogues containing linearly fused five- or seven-membered rings was also conducted and discussed. It was found that $5 \mathrm{~b}$ behaved as a $\mathrm{p}$-type organic semiconductor in solution-processed thin film transistors with a field effect mobility of up to $0.025 \mathrm{~cm}^{2} \mathrm{~V}^{-1} \mathrm{~s}^{-1}$.
\end{abstract}

\section{Introduction}

Pentacene (1a in Fig. 1a) is a leading p-type organic semiconductor for applications in light-weight, flexible and low-cost organic electronic devices, ${ }^{1}$ and has been used as a benchmark in comparison with new materials for applications in organic thin film transistors (OTFTs). ${ }^{2}$ Pentacene has been molecularly engineered with three strategies in order to modify electronic structure, tune molecular packing in the solid state, improve solubility and stability, and better understand its structureproperty relationship. As extensively studied, the first strategy is to substitute $\mathrm{H}$ atoms in pentacene with a variety of functional groups. ${ }^{3}$ The most successful example of this strategy is 6,13bis((triisopropylsilyl)ethynyl)-pentacene (1b in Fig. 1a), ${ }^{4}$ which is a solution-processed high-mobility $\mathrm{p}$-type semiconductor ${ }^{5,6}$

${ }^{a}$ Department of Chemistry, The Chinese University of Hong Kong, Shatin, New Territories, Hong Kong, China.E-mail: miaoqian@cuhk.edu.hk

${ }^{b}$ Department of Chemistry, National University of Singapore, 3 Science Drive 3, 117543, Singapore. E-mail: chmcc@nus.edu.sg

${ }^{c}$ Graduate School of Materials Science, Nara Institute of Science and Technology (NAIST), 8916-5 Takayama-cho, Ikoma 630-0192, Japan

${ }^{d}$ Division of Physical Science and Engineering and KAUST Catalysis Center, King Abdullah University of Science and Technology (KAUST), Thuwal 23955-6900, Kingdom of Saudi Arabia

$\dagger$ Electronic supplementary information (ESI) available: Synthetic procedures and characterization data for all new compounds; general experimental method; additional spectroscopic data; DFT calculation details; crystallographic data; and OTFT characterizations. CCDC 1468926 and 1468927. For ESI and crystallographic data in CIF or other electronic format see DOI: 10.1039/c6sc01795a

\$ These authors contributed equally to this work. with brickwork arrangement of $\pi$-planes. The second strategy is to replace $\mathrm{C}$ atoms in pentacene with hetero atoms, such as $\mathrm{B},{ }^{7}$ $\mathrm{N},{ }^{8}$ and S. ${ }^{9,10}$ Among the resultant heteropentacenes, $\mathrm{N}$-heteropentacenes were most extensively studied, and have recently arisen as a class of organic semiconductors with high performance in OTFTs. ${ }^{\mathbf{1 1}}$ The third strategy is to replace six-membered rings in pentacene with five- or seven-membered rings, leading to recently reported pentacene analogues containing $\mathrm{C}_{6}-\mathrm{C}_{5}-\mathrm{C}_{6}-$ $\mathrm{C}_{5}-\mathrm{C}_{6}{ }^{12-14}$ and $\mathrm{C}_{6}-\mathrm{C}_{7}-\mathrm{C}_{6}-\mathrm{C}_{7}-\mathrm{C}_{6}{ }^{15}$ polycyclic frameworks, such as 2-4 in Fig. 1a. With $20 \pi$ electrons, 2a and 3a both have two $\pi$ electrons less than pentacene, while 4 a has two more $\pi$ electrons. Therefore, their electronic structure and physical properties are distinctively different from those of pentacene. In this study, we explore a novel linearly fused pentacene analogue, benzo[4,5]cyclohepta[1,2-b]fluorene (5a in Fig. 1a), which contains an unprecedented $\mathrm{C}_{6}-\mathrm{C}_{5}-\mathrm{C}_{6}-\mathrm{C}_{7}-\mathrm{C}_{6}$ polycyclic framework. Unlike other pentacene analogues, $\mathbf{5 a}$ is a constitutional isomer of pentacene having both five- and seven-membered rings in the linear $\pi$-backbone with $22 \pi$ electrons. Besides the quinoidal resonance structure, one dipolar ionic resonance form $\left(\mathbf{5} \mathbf{a}^{\prime}\right)$ and one open-shell diradical form $\left(\mathbf{5} \mathbf{a}^{\prime \prime}\right)$ can be also drawn for 5a (Fig. 1b). The existence of one more aromatic sextet ring (shaded in blue) in $\mathbf{5} \mathbf{a}^{\prime}$ and $\mathbf{5} \mathbf{a}^{\prime \prime}$ suggests that these two resonance forms might make a significant contribution to the ground state structure. Like all other pentacene analogues, bulky triisopropylsilylethynyl (in 5b) or mesityl (in 5c) groups are introduced to the reactive sites so that soluble and stable materials can be obtained. Detailed below are their synthesis, ground-state structures, physical properties and their applications for OTFTs. A comparison with pentacene and other 
(a)

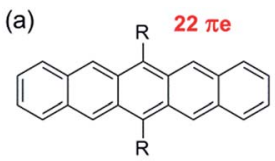

1a: $\mathrm{R}=\mathrm{H}$ 1b: $\mathrm{R}=\xi \equiv \mathrm{Si}^{\mathrm{P}} \mathrm{Pr}_{3}$ 1c: $R=$ mesity

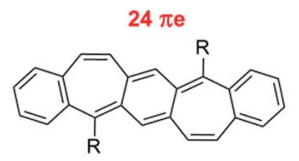

4a: $\mathrm{R}=\mathrm{H}$

4b: $R=\xi \equiv$ Si $^{i} \mathrm{Pr}_{3}$

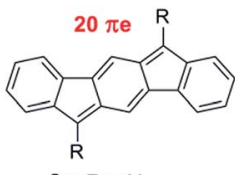

2a: $\mathrm{R}=\mathrm{H}$

2b: $R=\xi=\mathrm{Si}^{i} \mathrm{Pr}_{3}$

2c: $R=$ mesityl

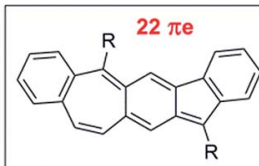

5a: $\mathrm{R}=\mathrm{H}$

5b: $\mathrm{R}=\xi \equiv \mathrm{Si}^{i} \mathrm{Pr}_{3}$

5c: $R=$ mesityl

(b)

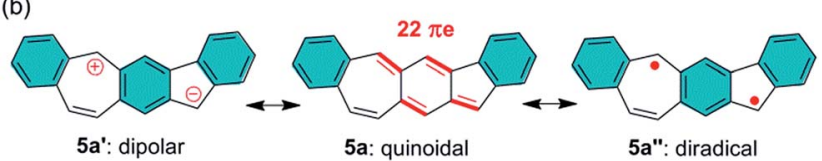

Fig. 1 (a) Chemical structures of pentacene and its analogues; (b) three typical resonance forms of $5 a$.

pentacene analogues is also made to better understand the structure-property relationship.

\section{Results and discussion}

\section{Synthesis and characterization}

Scheme 1 shows the synthesis of $\mathbf{5 b}$ and $\mathbf{5 c}$ starting from commercially available dimethyl 2,5-dibromoterephthalate 6, which was coupled with phenyl boronic acid and styrene subsequently in the Suzuki reaction and Heck reaction, respectively, resulting in the diester 8 . Pd/C-catalyzed hydrogenation of $\mathbf{8}$ followed by treatment with methanesulfonic acid at $100{ }^{\circ} \mathrm{C}$ led to cyclized product 10. Bromination of 10 and subsequent elimination of $\mathrm{HBr}$ yielded the dehydrogenated dione 11. X-Ray crystallographic analysis of the single crystals of 11 revealed a non-planar geometry (Fig. S6 in ESI $\dagger$ ), which can explain its moderate solubility in common organic solvents. Nucleophilic addition of (triisopropylsilyl)ethynyl and mesityl lithium to 11 resulted in the diols $\mathbf{1 2 b}$ and $12 \mathrm{c}$, respectively, which both were obtained as a mixture of cis and trans-isomers. Reduction of intermediate diols $\mathbf{1 2 b}$ and $12 \mathbf{c}$ in THF with a solution of concentrated $\mathrm{HCl}$ that was saturated with $\mathrm{SnCl}_{2}$ led to $\mathbf{5 b}$ and $\mathbf{5 c}$, respectively, both as deep green solids in moderate yield. Dione 10 was also synthesized from 2,5-dibromo- $p$-xylene in a similar approach in higher overall yield but more steps (Scheme S1 in ESI $\dagger$ ). The ${ }^{1} \mathrm{H}$ NMR spectra of $\mathbf{5 b}$ and $\mathbf{5 c}$ (ESI $\dagger$ ) both show sharp splitting and narrow line widths indicating that they behave more like closed-shell compounds in the ground state. ${ }^{16}$

The redox behaviors of $\mathbf{5 b} \mathbf{b} \mathbf{5} \mathbf{c}$ in solution were investigated with cyclic voltammetry. In the test window of cyclic voltammetry, $5 \mathbf{b}$ exhibits a reversible reduction $\left(\mathbf{5 b} / \mathbf{5} \mathbf{b}^{-}\right)$wave and an irreversible oxidation $\left(\mathbf{5 b} / \mathbf{5} \mathbf{b}^{+}\right)$wave, while $\mathbf{5} \mathbf{c}$ exhibits a reversible reduction $\left(\mathbf{5 c} / \mathbf{5} \mathbf{c}^{-}\right)$wave and a reversible oxidation $\left(\mathbf{5 c} / \mathbf{5} \mathbf{c}^{+}\right)$
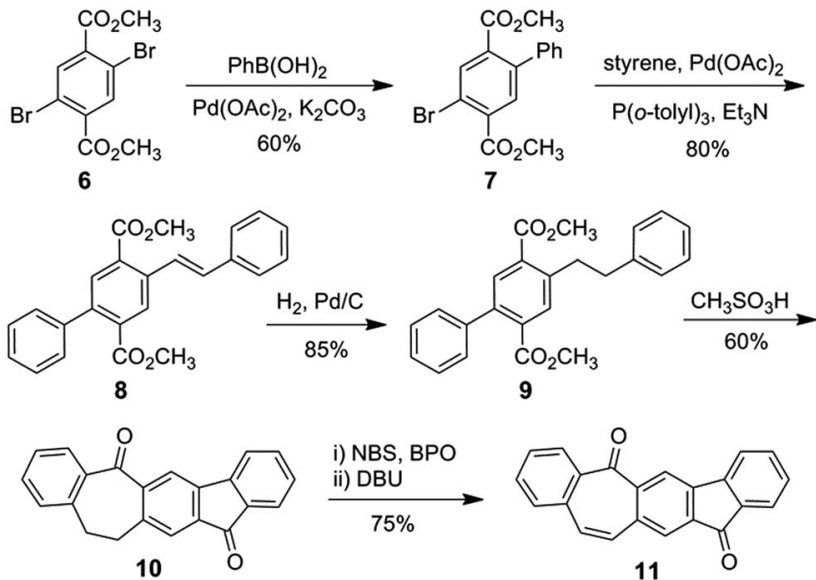

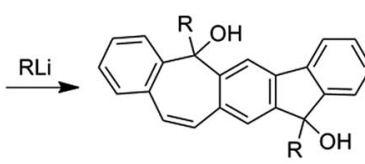

12b: $R=\xi \equiv \operatorname{SiPr}_{3}(95 \%)$

12c: $R=$ mesityl $(95 \%)$

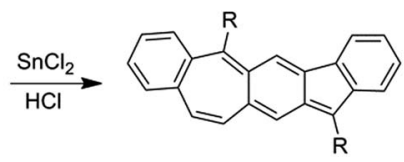

5b: $R=\xi \equiv$ SiPr $_{3}(65 \%)$

5c: $R=$ mesityl $(70 \%)$
Scheme 1 Synthesis of $5 b / 5 c$.

wave as shown in Fig. 2a. The half-wave reduction potentials $\left(E_{1 / 2}^{\mathrm{red}}\right)$ of $5 \mathbf{b}$ and $5 \mathbf{c}$ are $-1.30 \mathrm{~V}$ and $-1.77 \mathrm{~V}$ versus the ferrocenium/ferrocene $\left(\mathrm{Fc}^{+} / \mathrm{Fc}\right)$ redox couple, respectively, from which the lowest unoccupied molecular orbital (LUMO) energy levels of $\mathbf{5 b}$ and $\mathbf{5 c}$ are estimated as $-3.80 \mathrm{eV}$ and $-3.33 \mathrm{eV}$, respectively. ${ }^{17}$ Similarly, the highest occupied molecular orbital (HOMO) energy levels of $\mathbf{5 b}$ and $\mathbf{5 c}$ are estimated as $-5.36 \mathrm{eV}$ and $-5.27 \mathrm{eV}$ from the half-wave oxidation potential $\left(E_{1 / 2}^{\mathrm{ox}}=0.26 \mathrm{~V}\right.$ and $0.17 \mathrm{~V}$ vs. $\mathrm{Fc}^{+} / \mathrm{Fc}$, respectively). ${ }^{17}$ The lower LUMO and HOMO energy levels of $\mathbf{5 b}$ in comparison with $\mathbf{5 c}$ can be attributed to the facts that the ethynyl substituents with sp hybridized carbons in $\mathbf{5 b}$ are electron withdrawing and the substituting phenyl groups in $\mathbf{5 c}$ are almost orthogonal to the polycyclic backbone with poor conjugation. Table 1 compares $\mathbf{5 b} / \mathbf{5 c}$ with those of the related molecules 1-4 in terms of electrochemical potentials and frontier molecular orbital energy levels. It is found that $\mathbf{5 b}$ and $\mathbf{5} \mathbf{c}$ have a higher HOMO energy level and a lower LUMO energy level than the corresponding pentacene derivatives $\mathbf{1 b}$ and $\mathbf{1 c}$, respectively. Furthermore, the oxidation potential of $\mathbf{5 b}$ is almost the same as that of $\mathbf{4 b}$, and the reduction potential of $\mathbf{5 b}$ is close to that of $\mathbf{2 b}$. Molecule $\mathbf{5 c}$ has a reduction potential close to that of $\mathbf{3 c}$, which has the same mesityl substituents. These findings are in agreement with the assumption that the first reduction of $5 \mathbf{b} / \mathbf{5 c}$ occurs on the fivemembered ring leading to an aromatic cyclopentadienide anion and the first oxidation of $\mathbf{5 b} / \mathbf{5} \mathbf{c}$ occurs on the seven-membered ring leading to an aromatic cycloheptatrienium cation.

As shown in Fig. 2b, $\mathbf{5 b}$ and $\mathbf{5 c}$ in $\mathrm{CH}_{2} \mathrm{Cl}_{2}$ exhibit electronic absorption spectra very different from those of pentacene and other analogues. The broad absorption band in the visible-near infrared (vis-NIR) region could be attributed to the HOMO $\rightarrow$ LUMO transition based on time-dependent density functional theory (TDDFT) calculations (ESI $\dagger$ ). The intense absorption 
(a)

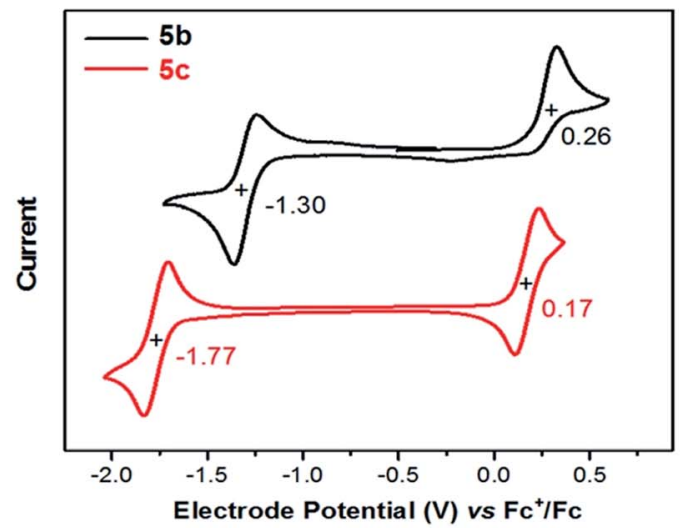

(b)

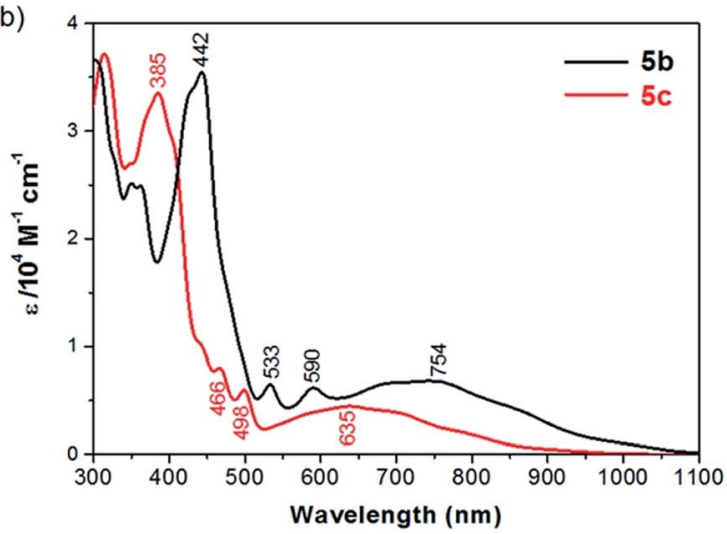

Fig. 2 (a) Cyclic voltammograms of $5 b$ and $5 c$ recorded in $\mathrm{CH}_{2} \mathrm{Cl}_{2}$ with $\mathrm{Fc}^{+} / \mathrm{Fc}$ as the external standard at a scan rate of $50 \mathrm{mV} \mathrm{s}^{-1}$; (b) UVvis-NIR absorption of $5 \mathrm{~b}$ and $5 \mathrm{c}$ in $\mathrm{CH}_{2} \mathrm{Cl}_{2}$.

Table 1 Electrochemical potentials and frontier molecular orbital energy levels of $1-5$

\begin{tabular}{llllll}
\hline & $E_{1 / 2}^{\mathrm{red} a} / \mathrm{V}$ & $E_{1 / 2}^{\mathrm{ox} a} / \mathrm{V}$ & $\mathrm{LUMO}^{b} / \mathrm{eV}$ & $\mathrm{HOMO}^{c} / \mathrm{eV}$ & $E_{\mathrm{g}}^{\mathrm{EC} d} / \mathrm{eV}$ \\
\hline $\mathbf{1 \mathbf { b } ^ { 1 8 }}$ & -1.50 & 0.37 & -3.60 & -5.47 & 1.87 \\
$\mathbf{1 c}^{10}$ & -1.92 & 0.22 & -3.18 & -5.32 & 2.14 \\
$\mathbf{2} \mathbf{b}^{12}$ & -1.15 & 0.74 & -3.95 & -5.84 & 1.89 \\
$\mathbf{2 c}^{13}$ & -1.58 & 0.64 & -3.52 & -5.74 & 2.22 \\
$\mathbf{3 c ^ { 1 4 }}$ & -1.13 & 0.13 & -3.97 & -5.23 & 1.26 \\
$\mathbf{4 \mathbf { b } ^ { 1 5 }}$ & -1.66 & 0.12 & -3.44 & -5.32 & 1.78 \\
$\mathbf{5 b}$ & -1.30 & 0.26 & -3.80 & -5.36 & 1.56 \\
$\mathbf{5 c}$ & -1.77 & 0.17 & -3.33 & -5.27 & 1.94
\end{tabular}

${ }^{a} E_{1 / 2}^{\mathrm{red}}$ and $E_{1 / 2}^{\mathrm{ox}}$ are the half-wave potential $\left(v s . \mathrm{Fc}^{+} / \mathrm{Fc}\right.$ ) of the first oxidation and reduction wave, respectively. ${ }^{b}$ Estimated from LUMO $=$ $-5.10-E_{\text {red }}(\mathrm{eV}) .{ }^{c}$ Estimated from HOMO $=-5.10-E_{\mathrm{Ox}}(\mathrm{eV})$. ${ }^{d} E_{\mathrm{g}}^{\mathrm{EC}}=$ LUMO - HOMO.

band at the UV-vis region can be mainly attributed to the HOMO-1 $\rightarrow$ LUMO and HOMO $\rightarrow$ LUMO +1 transitions. The optical energy gaps $\left(E_{\mathrm{g}}^{\mathrm{Opt}}\right)$ of $\mathbf{5 b}$ and $\mathbf{5} \mathbf{c}$ were estimated to be $1.13 \mathrm{eV}$ and $1.25 \mathrm{eV}$, respectively, from the lowest energy absorption onset. The optical energy gap of $\mathbf{5 b} / \mathbf{5 c}$ is significantly smaller than the HOMO-LUMO gap $\left(E_{\mathrm{g}}^{\mathrm{EC}}\right)$ as estimated from electrochemical potentials. A similar phenomenon was also observed from azulene, which has an optical energy gap of $1.75 \mathrm{eV}$ (about $710 \mathrm{~nm})^{19}$ and an electrochemical energy gap of
$2.35 \mathrm{eV} \cdot{ }^{20}$ Azulene has a lower transition energy than anticipated from the HOMO-LUMO gap because the excited state of azulene has a smaller repulsive energy between the two electrons occupying HOMO and LUMO due to the nonalternant nature of azulene. ${ }^{21-23}$ This explanation may also account for the smaller optical energy gap of $\mathbf{5 b} / \mathbf{5 c}$, whose pentacyclic backbone is also nonalternant.

Single crystals of $\mathbf{5 c}$ selected for X-ray crystallographic analysis were grown by slow diffusion of acetonitrile into a solution in $\mathrm{CH}_{2} \mathrm{Cl}_{2}{ }^{24}$ It is found that the unit cell of this crystal contains crystallized solvent $\left(\mathrm{CH}_{3} \mathrm{CN}\right)$ molecules with disorder as shown in Fig. 3a. In the crystal structure of $5 \mathbf{c} \cdot \mathrm{CH}_{3} \mathrm{CN}$, the pentacyclic backbone of $\mathbf{5 c}$ (Fig. 3b) is essentially flat and is almost perpendicular to the substituting mesityl groups with dihedral angles of $80.2^{\circ}$ and $87.9^{\circ}$. Examination of the bond lengths in the central six-membered ring reveals four $\mathrm{C}-\mathrm{C}$ single bonds (C5a-C12a, C5a-C6, C6a-C11a, C11a-C12) with bond lengths of 1.42-1.48 $\AA$ and two C-C double bonds (C6-C6a, C12-C12a) with bond lengths of $1.35-1.37 \AA .{ }^{25}$ Moreover, the central sixmembered ring is bonded to $\mathrm{C} 5$ and $\mathrm{C} 11$ with relatively short bond lengths (C5-C5a: $1.39 \AA$; C11-C11a: $1.37 \AA$ ). The above bond lengths are similar to the corresponding bond lengths in

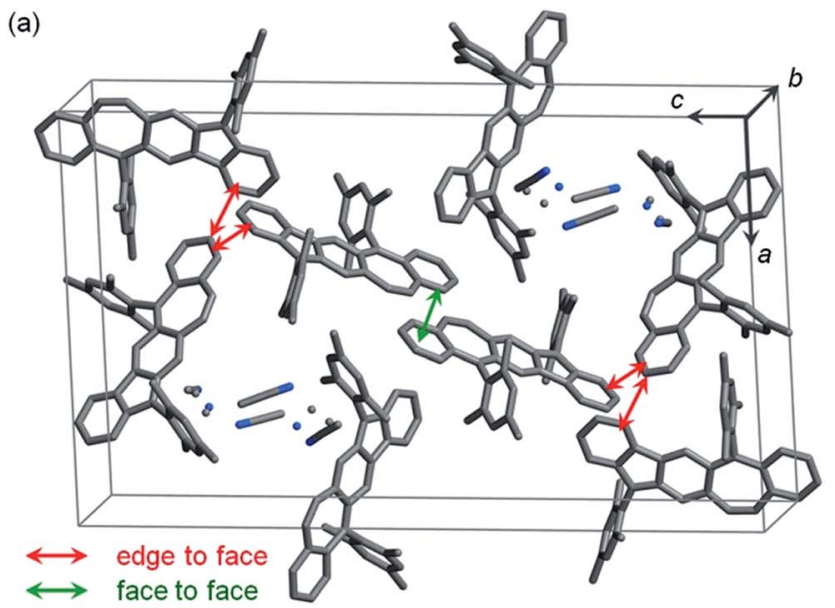

(b)

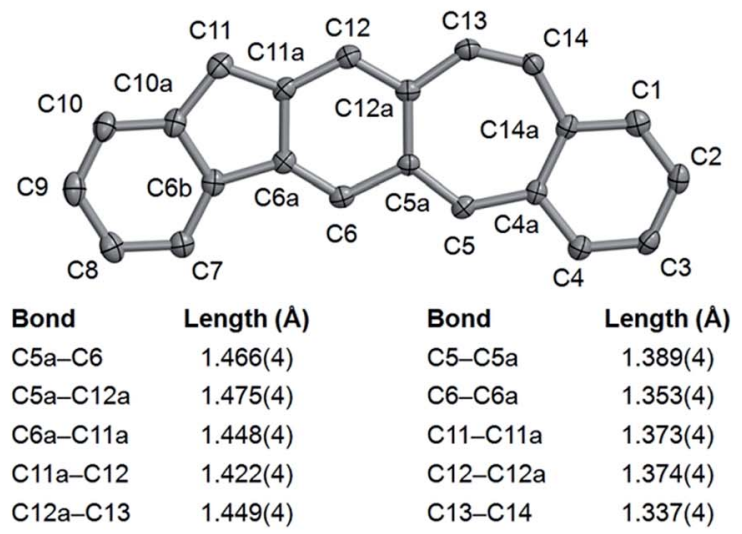

Fig. 3 Crystallographic structure of $5 \mathrm{c} \cdot \mathrm{CH}_{3} \mathrm{CN}$ with hydrogen atoms removed for clarification: (a) a unit cell with disordered atoms of $\mathrm{CH}_{3} \mathrm{CN}$ shown as dots; (b) the pentacyclic backbone of $5 \mathrm{c}$ with carbon atoms labeled and some bond lengths highlighted (carbon atoms are shown as ellipsoids at the $50 \%$ probability level). 
the crystallographic structures of $2 \mathbf{b},{ }^{12} \mathbf{2 c},{ }^{13}$ and $4 \mathbf{b},{ }^{15}$ indicating a $p$-quinodimethane structure with large bond length alternation. In addition to the $\mathrm{C} 5-\mathrm{C} 5$ a bond, the seven-membered ring contains another $\mathrm{C}-\mathrm{C}$ double bond (C13-C14) with a bond length $(1.34 \AA)$ typical for alkenes. Neighboring molecules of 5c exhibit poor $\pi-\pi$ interactions between the pentacyclic backbones presumably because the bulky mesityl substituting groups block $\pi-\pi$ interactions. Only a small face-to-face overlap with a $\pi$-to- $\pi$ distance of $3.40 \AA$ and a small number of edge-toface contacts are observed as shown in Fig. 3a.

\section{Computational studies}

Density functional theory (DFT) calculations at the (U)CAMB3LYP/6-31G* level of theory were conducted to better understand the ground state structures of $\mathbf{5 a - c . ~ I t ~ i s ~ f o u n d ~ t h a t ~ t h e ~}$ solution of the open-shell singlet (OS) state has a lower energy than the closed-shell (CS) state for $\mathbf{5 b}$, thus defining an openshell singlet ground state. The singly occupied molecular orbitals (SOMO) of the $\alpha$ and $\beta$ spins are partially disjointed (Fig. 4a), in accordance with a calculated small diradical character $\left(y_{0}=4.7 \%\right)$. The spins are delocalized throughout the whole $\pi$-conjugated framework, including the $\mathrm{C}-\mathrm{C}$ triple bonds (Fig. 4a). This result indicates that the diradical resonance form $\mathbf{5} \mathbf{a}^{\prime \prime}$ indeed contributes to the ground state of $\mathbf{5 b}$ to a certain extent. On the other hand, $\mathbf{5 a}$ and $\mathbf{5 c}$ are calculated to have a closed-shell ground state with zero diradical character. The HOMO and LUMO of $\mathbf{5 a}$ and $\mathbf{5 c}$ are delocalized through the whole backbone with slight segregation as shown in Fig. S1 $(\mathrm{ESI}) \dagger$ and $4 \mathrm{a}$, respectively. The above results suggest that the
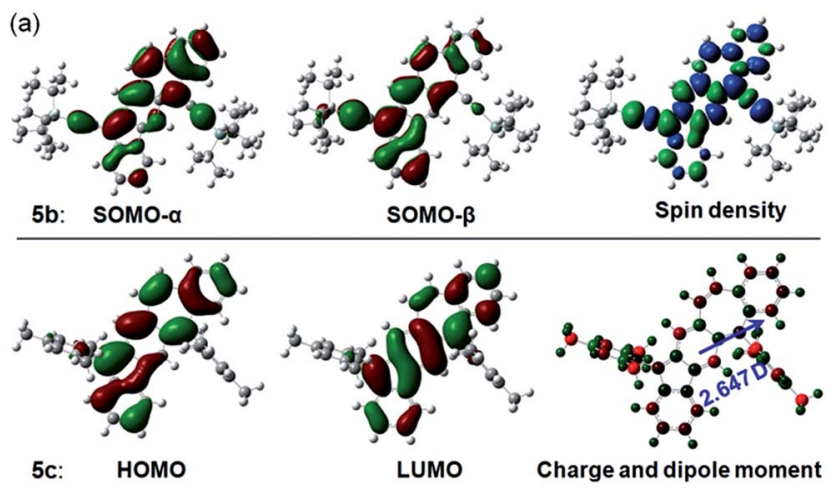

(b) 1a

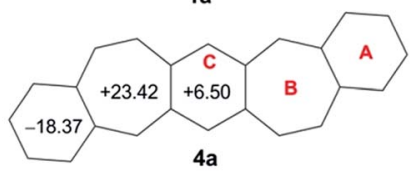

$4 a$

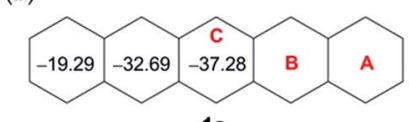

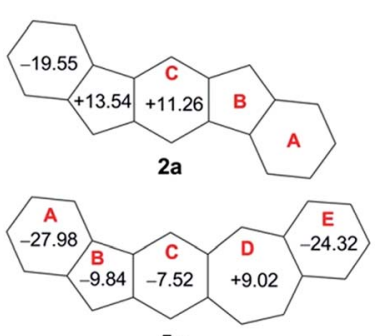

5 a
Fig. 4 (a) Calculated frontier MO profiles of $5 b$ and $5 c$, spin density map of singlet diradical of $5 \mathrm{~b}$, and Mulliken charge distribution ( -0.528 (red) to 0.528 (green)) and dipole moment of 5c; (b) calculated NICS(1) zz values for pentacene and its analogues. ethynyl substituents can help to stabilize the diradical resonance form. The dipole moments of $\mathbf{5 b}$ and $\mathbf{5 c}$ were calculated to be 3.179 and 2.647 debye, respectively, at the CAM-B3LYP/6$31 \mathrm{G}^{*}$ level of DFT, which are larger than that of azulene $(1.268$ debye) as calculated with the same method. This reflects the contribution of the dipolar ionic form $\mathbf{5} \mathbf{a}^{\prime}$ to the ground state of both $\mathbf{5 b}$ and $\mathbf{5 c}$.

To provide further insight into the aromaticity of each individual ring of these $\pi$-conjugated polycyclic hydrocarbons, nucleus independent chemical shift (NICS) of 1a, 2a, 4a and 5a were also calculated. Fig. 4b compares the calculated NICS(1)zz values of these molecules. Large negative values are found for all rings in 1a, in agreement with its known aromatic character. In 2a, a large negative value is calculated for ring A while both ring $\mathrm{B}$ and ring $\mathrm{C}$ show positive values, indicating that it can be regarded as a dibenzo-fused anti-aromatic $s$-indacene structure. In $\mathbf{4 a}$, the central ring $\mathrm{C}$ is less positive compared with that in 2a, indicating its less anti-aromatic character. The sevenmembered ring $\mathrm{B}$ however has a large positive value. In $\mathbf{5 a}$, the central ring $\mathrm{C}$ and the five-membered ring $\mathrm{B}$ both become negative, and the seven-membered ring $\mathrm{D}$ is much less positive than that in $\mathbf{4 a}$, indicating that a balance of three resonance forms leads to a weak aromatic character of the central $\mathrm{C}_{5}-\mathrm{C}_{6}-$ $\mathrm{C}_{7}$ framework. The outmost benzenoid rings (A and E) are aromatic with large negative values. In agreement with the negative NICS value for the central ring $\mathrm{C}$ in $\mathbf{5 a}$, the protons on the same ring in $\mathbf{5 b}$ exhibit a downfield singlet peak at $8.95 \mathrm{ppm}$ as well as a singlet peak $7.10 \mathrm{ppm}$ in the ${ }^{1} \mathrm{H}$ NMR spectrum. In comparison to this, the corresponding protons on the central ring $\mathrm{C}$ in $\mathbf{2} \mathbf{b}^{\mathbf{1 2}}$ and $\mathbf{4} \mathbf{b}^{\mathbf{1 5}}$ exhibit singlet peaks at 7.26 and 7.16 ppm, respectively, in the ${ }^{1} \mathrm{H}$ NMR spectra taken from the same solution $\left(\mathrm{CDCl}_{3}\right)$.

\section{Semiconductor properties}

One interesting aspect of $\mathbf{5 b}$ is its semiconducting properties since it is a constitutional isomer of pentacene $\mathbf{1 b}$, a well-known solution-processed p-type organic semiconductor. To test the semiconducting properties of $\mathbf{5 b}$, top-contact transistors were fabricated on dip-coated films of $\mathbf{5 b}$, which were formed by immersing a $\mathrm{SiO}_{2} / \mathrm{Si}$ substrate in a solution of $5 \mathbf{b}\left(2.5 \mathrm{mg} \mathrm{mL}^{-1}\right)$ in $n$-hexane and then pulling it up with a constant speed of 5.3 $\mu \mathrm{m} \mathrm{s}^{-1}$. As shown in the polarized-light micrograph in Fig. 5a, the dip-coated films of $\mathbf{5 b}$ on $\mathrm{SiO}_{2}$ are composed of crystalline fibers roughly aligned in the pulling direction; X-ray diffraction patterns from the films of $\mathbf{5 b}$ (Fig. S4 in ESI $\dagger$ ) exhibit an intense peak at $d$-spacing of $18.88 \AA\left(2 \theta=4.68^{\circ}\right)$ accompanied with three higher-order peaks at $9.44 \AA\left(2 \theta=9.37^{\circ}\right), 6.29 \AA(2 \theta=$ $\left.14.07^{\circ}\right)$, and $4.72 \AA\left(2 \theta=18.80^{\circ}\right)$, indicating a crystalline film with a layered structure. As measured in air from these devices, 5b functions as a p-type semiconductor with a field-effect mobility of up to $0.025 \mathrm{~cm}^{2} \mathrm{~V}^{-1} \mathrm{~s}^{-1}$ (average $0.018 \pm$ $0.003 \mathrm{~cm}^{2} \mathrm{~V}^{-1} \mathrm{~s}^{-1}$ ). Fig. 5b shows the transfer $I-V$ curve in the saturation region for one of the best-performing OTFTs of $\mathbf{5 b}$ measured in air. From this transfer $I-V$ curve, the field mobility is extracted using the equation: $I_{\mathrm{DS}}=\left(\mu W C_{\mathrm{i}} / 2 L\right)\left(V_{\mathrm{G}}-V_{\mathrm{T}}\right)^{2}$, where $I_{\mathrm{DS}}$ is the drain current, $\mu$ is field-effect mobility, $C_{\mathrm{i}}$ is the 
(a)

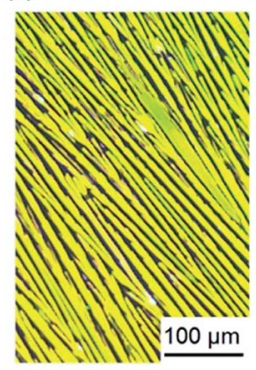

(b)

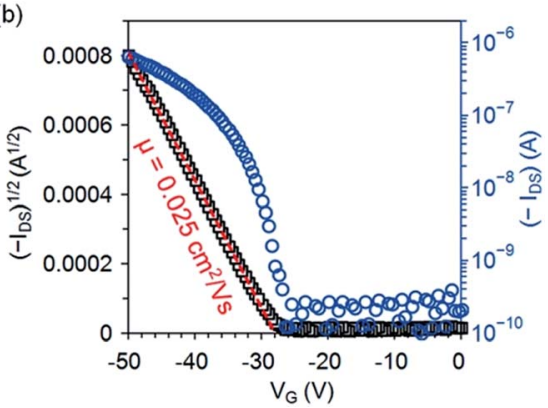

Fig. 5 (a) Reflection polarized-light micrograph for a dip-coated film of $5 \mathrm{~b}$ on $\mathrm{SiO}_{2} ;(\mathrm{b})$ drain current $\left(I_{\mathrm{DS}}\right)$ versus gate voltage $\left(V_{\mathrm{G}}\right)$ with drain voltage $\left(V_{D S}\right)$ at $-50 \mathrm{~V}$ for an OTFT of $5 \mathrm{~b}$ with an active channel of $W=$ $1 \mathrm{~mm}$ and $L=100 \mu \mathrm{m}$ as measured in air.

capacitance per unit area $\left(11 \mathrm{nF} \mathrm{cm}^{-2}\right)$ for the $300 \mathrm{~nm}$-thick dielectric layer of $\mathrm{SiO}_{2}, W$ is the channel width, $L$ is the channel length, and $V_{\mathrm{G}}$ and $V_{\mathrm{T}}$ are the gate and threshold voltage, respectively. The mobility of $\mathbf{5 b}$ is lower than those of $\mathbf{1} \mathbf{b}^{\mathbf{2 6}}$ and $\mathbf{4} \mathbf{b}^{\mathbf{1 5}}$ in solution-processed OTFTs on bare $\mathrm{SiO}_{2}$ by one order of magnitude likely because of the unsymmetrical arrangement of silylethynyl substituting groups, which presumably leads to unfavorable molecular packing with poor $\pi-\pi$ interactions.

\section{Conclusions}

In summary, the above study puts forth a new class of conjugated polycyclic molecules that contain a $\mathrm{C}_{6}-\mathrm{C}_{5}-\mathrm{C}_{6}-\mathrm{C}_{7}-\mathrm{C}_{6}$ framework isomeric to pentacene. The benzo[4,5]cyclohepta $[1,2-b]$ fluorene derivatives $5 \mathbf{b} / \mathbf{5 c}$ display different optical and electrochemical properties in comparison with pentacene and its analogues 2-4. As found from the crystal structure, $\mathbf{5 b}$ has a nearly flat pentacyclic $\pi$-backbone with a quinoidal core. The computational studies indicate that the dipolar ionic resonance form contributes to the ground states of both $\mathbf{5 b}$ and $\mathbf{5 c}$, while the diradical characters in the ground state depends on the substituting groups. $\mathbf{5 b}$ has a calculated diradical character $\left(y_{0}\right)$ in the ground state as small as $4.7 \%$, which is not spectroscopically detectable, while $\mathbf{5 c}$ has a closed-shell ground state with zero diradical character. As a constitutional isomer of pentacene $\mathbf{1 b}, \mathbf{5 b}$ functions as a p-type organic semiconductor in solution-processed OTFTs with field effect mobility of up to $0.025 \mathrm{~cm}^{2} \mathrm{~V}^{-1} \mathrm{~s}^{-1}$. As an extension from this study, synthesis of novel polycyclic arenes containing both five- and seven membered rings is in progress in our laboratories. These molecules may exhibit interesting physical properties that are not available for their benzenoid analogues as suggested by a recent theoretical study. ${ }^{27}$

\section{Acknowledgements}

We are grateful to Prof. Michael M. Haley (University of Oregon) and Prof. Yoshito Tobe (Osaka University) for their kind support and helpful discussion. X. Yang and Q. Miao thank financial support from the Research Grants Council of Hong Kong (project number: GRF402412, CRF C4030-14G). X. Shi and C.

Chi thank financial support from MOE Tier 1 grant (R-143-000623-112), Tier 2 grant (MOE2014-T2-1-080) and Tier 3 programme (MOE2014-T3-1-004). N. Aratani and H. Yamada thank support from the Grants-in-Aid for Scientific Research from JSPS (No. 16H02286, 26105004 and 26288038) and CREST, JST. T. P. Gonçalves and K.-W. Huang acknowledge the financial support from KAUST including NOOR 2 and Shaheen 2 HPC Facilities.

\section{Notes and references}

1 T. Sekitani, U. Zschieschang, H. Klauk and T. Someya, Nat. Mater., 2010, 9, 1015-1022.

2 A. R. Murphy and J. M. J. Fréchet, Chem. Rev., 2007, 107, 1066-1096.

3 (a) M. Bendikov, F. Wudl and D. F. Perepichka, Chem. Rev., 2004, 104, 4891-4946; (b) J. E. Anthony, Angew. Chem., Int. Ed., 2008, 47, 452-483.

4 J. E. Anthony, J. S. Brooks, D. L. Eaton and S. R. Parkin, J. Am. Chem. Soc., 2001, 123, 9482-9483.

5 Y. Diao, B. C.-K. Tee, G. Giri, J. Xu, D. H. Kim, H. A. Becerril, R. M. Stoltenberg, T. H. Lee, G. Xue, S. C. B. Mannsfeld and Z. Bao, Nat. Mater., 2013, 12, 665-671.

6 D. Liu, Z. He, Y. Su, Y. Diao, S. C. B. Mannsfeld, Z. Bao, J. Xu and Q. Miao, Adv. Mater., 2014, 26, 7190-7196.

7 A. Caruso Jr., M. A. Siegler and J. D. Tovar, Angew. Chem., Int. Ed., 2010, 49, 4213-4217.

8 U. H. F. Bunz, J. U. Engelhart, B. D. Lindner and M. Schaffroth, Angew. Chem., Int. Ed., 2013, 52, 3810-3821.

9 Q. Ye, J. Chang, X. Shi, G. Dai, W. Zhang, K.-W. Huang and C. Chi, Org. Lett., 2014, 16, 3966-3969.

10 X. Shi, W. Kueh, B. Zheng, K.-W. Huang and C. Chi, Angew. Chem., Int. Ed., 2015, 54, 14412-14415.

11 (a) Q. Miao, Adv. Mater., 2014, 26, 5541-5549; (b) Q. Miao, Synlett, 2012, 23, 326-336.

12 D. T. Chase, A. G. Fix, B. D. Rose, C. D. Weber, S. Nobusue, C. E. Stockwell, L. N. Zakharov, M. C. Lonergan and M. M. Haley, Angew. Chem., Int. Ed., 2011, 50, 11103-11106.

13 D. T. Chase, A. G. Fix, S. J. Kang, B. D. Rose, C. D. Weber, Y. Zhong, L. N. Zakharov, M. C. Lonergan, C. Nuckolls and M. M. Haley, J. Am. Chem. Soc., 2012, 134, 10349-10352.

14 A. Shimizu, R. Kishi, M. Nakano, D. Shiomi, K. Sato, T. Takui, I. Hisaki, M. Miyata and Y. Tobe, Angew. Chem., Int. Ed., 2013, 52, 6076-6079.

15 X. Yang, D. Liu and Q. Miao, Angew. Chem., Int. Ed., 2014, 53, 6786-6790.

16 S. Das and J. Wu, in Polycyclic Arenes and Heteroarenes: Synthesis, Properties and Applications, ed. Q. Miao, Wiley VCH, Weinheim, 2016, ch. 1, pp. 3-36.

17 The commonly used formal potential of the redox couple of ferrocenium/ferrocene $\left(\mathrm{Fc}^{+} / \mathrm{Fc}\right)$ in the Fermi scale is $-5.1 \mathrm{eV}$, which is calculated on the basis of an approximation neglecting solvent effects using a work function of $4.46 \mathrm{eV}$ for the normal hydrogen electrode (NHE) and an electrochemical potential of $0.64 \mathrm{~V}$ for $\left(\mathrm{Fc}^{+} / \mathrm{Fc}\right)$ versus NHE. C. M. Cardona, W. Li, A. E. Kaifer, D. Stockdale and G. C. Bazan, Adv. Mater., 2011, 23, 2367-2371. 
18 Z. Liang, Q. Tang, J. Xu and Q. Miao, Adv. Mater., 2011, 23, 1535-1539.

19 R. S. H. Liu, J. Chem. Educ., 2002, 79, 183-185.

20 S. Förster, T. Hahn, C. Loose, C. Röder, S. Liebing, W. Seichter, F. Eißmann, J. Kortus and E. Weber, J. Phys. Org. Chem., 2012, 25, 856-863.

21 D. M. Lemal and G. D. Goldman, J. Chem. Educ., 1988, 65, 923-925.

22 J. Michl and E. W. Thulstrup., Tetrahedron, 1976, 32, 205209.

23 R. Gleiter, G. Haberhauer, Aromaticity and Other Conjugation Effects, Wiley VCH, Weinheim, 2012, pp. 70-72.

24 Crystallographic data for $5 \mathrm{c} \cdot \mathrm{CH}_{3} \mathrm{CN}: \mathrm{C}_{42} \mathrm{H}_{37} \mathrm{~N} . M_{\mathrm{w}}: 555.72$; monoclinic; space group $P 22_{1} / n ; a=20.925(2) \AA, b=$
8.4456(10) $\mathrm{A}, \quad c=34.677(4) \AA, \quad \beta=91.177(3)^{\circ}, \quad V=$ 6126.9(12) $\AA^{3} ; Z=8 ; \rho_{\text {calcd }}=1.205 \mathrm{Mg} \mathrm{m}^{-3} ; R_{1}=0.0652$, $\mathrm{w} R_{2}=0.1536(I>2 \sigma(I)) ; R_{1}=0.1248, \mathrm{w} R_{2}=0.1851$ (all data). CCDC No. 1468927.

25 The bond length is 1.45-1.46 $\AA$ for a typical single bond between two $\mathrm{sp}^{2}$ carbon atoms, 1.38-1.40 $\AA$ for a typical $\mathrm{C}-\mathrm{C} 1.5$ bond in arenes, and 1.31-1.34 $\AA$ for a typical C-C double bond in alkenes. See: E. V. Anslyn and D. A. Dougherty, Modern Physical Organic Chemistry, University Science Books, Sausalito, 2004, ch. 1, p. 22.

26 M. M. Payne, S. R. Parkin, J. E. Anthony, C.-C. Kuo and T. N. Jackson, J. Am. Chem. Soc., 2005, 127, 4986-4987.

27 M. Nakano, K. Fukuda and B. Champagne, J. Phys. Chem. C, 2016, 120, 1193-1207. 